\title{
POLYMORPHISM FOR DIRECTION OF COIL IN PARTULA SUTURALIS: BEHAVIOURAL ISOLATION AND POSITIVE FREQUENCY DEPENDENT SELECTION
}

\author{
MICHAEL S. JOHNSON \\ Department of Zoology, University of Western Australia, Nedlands, Western Australia \\ 6009.
}

Received 22.iii.82

\begin{abstract}
SUMMARY
Partula suturalis is unusual among snails in being polymorphic for direction of shell coiling. Polymorphic populations of $P$. suturalis occur in narrow clines between areas of monomorphic dextral or sinistral populations. The distribution of dextral populations coincides with the distribution of the sinistral species $P$. mooreana, $P$. tohiveana and $P$. olympia, suggesting character displacement for reproductive isolation. Chirality affects courtship behaviour, and no-choice mating experiments show that pairs with opposite coil mate only 20 per cent as frequently as do pairs with the same coil. Fewer young are produced by these mixed pairs. Fertilities of dextral and sinistral $P$. suturalis are the same in a population composed of equal frequencies of the two morphs. However, among wild-caught snails from a population in which sinistrals occur at low frequency, the rare morph produces fewer young than the common morph. The effects of chirality on behavioural isolation result in selection against the rare morph, accounting for the rarity of polymorphic populations. Such positive frequency dependent selection is capable of maintaining the stability of hybrid zones.
\end{abstract}

\section{INTRODUCTION}

AlTHOUGH the direction of coiling in snails may be either dextral or sinistral, polymorphism for chirality is uncommon. Even in genera which include both sinistral and dextral species, polymorphic species are unusual. For example, of the 12 named species of Partula on Tahiti and Moorea, 8 are dextral, 3 sinistral, and only $P$. suturalis and $P$. otaheitana are polymorphic for direction of coiling (Crampton, 1916, 1932; Murray and Clarke, 1980). In $P$. suturalis, sinistrality is inherited as a simple Mendelian dominant with delayed expression, the genotype of the maternal parent determining the phenotype of the offspring (Murray and Clarke, 1976). Even in these polymorphic species, however, most populations are monomorphic. In $P$. suturalis on the island of Moorea, for example, there is an area effect, in which monomorphic dextral populations are connected to monomorphic sinistral populations by steep clines (Clarke and Murray, 1969). This consistent uniformity of a potentially variable character implies strong stabilizing selection, and raises questions of the origin of the anomalous polymorphic populations.

The distribution of dextral populations of $\boldsymbol{P}$. suturalis coincides with the distribution of the sinistral species $P$. mooreana, $P$. tohiveana and $P$. olympia. This coincidence and the mutual exclusion of pairs of sinistral species of Partula suggest character displacement for reproductive isolation 
(Clarke and Murray, 1969; Murray and Clarke, 1980). The behavioural basis for such isolation is that in matings of snails of the opposite coil, the animals attempt intromission in the wrong place (Lipton and Murray, 1979). Clarke and Murray (1969; Murray and Clarke, 1980) refer to unpublished data which indicate that assortative mating occurs in polymorphic populations of $P$. suturalis.

If mating is less likely to occur between snails of opposite coil, individuals of the rarer morph will be less likely to mate. The resultant selection against the rare morph would favour monomorphism. Thus, if correct, the hypothesis that chirality is an isolating mechanism could explain both the variation among populations of $P$. suturalis and the tendency towards monomorphism. This paper reports tests of the effect of chirality on mating frequency and fertility, and selection against rare coil types in $P$. suturalis.

\section{Materials AND Methods}

(i) Mating experiments

$P$. suturalis were collected from polymorphic populations in Uufau and Morioahu valleys, Moorea $\left(17^{\circ} 30^{\prime} \mathrm{S}, 149^{\circ} 50^{\prime} \mathrm{W}\right)$. Individual snails were maintained in isolation in $9 \mathrm{~cm}$ plastic petri dishes, with a diet of oatmeal, lettuce, and powdered cuttlebone. Animals used for mating included wildcaught and lab-reared juveniles and wild-caught adults which had stopped producing young for at least 12 months in isolation, assuring depletion of stored sperm from previous matings. Maturity was recognized by the presence of a reflected lip on the shell (Murray and Clarke, 1966).

No-choice matings were conducted by placing pairs of snails in clear plastic boxes $(11.5 \times 11.5 \times 3.3 \mathrm{~cm})$. These matings included 14 dextral pairs, 20 sinistral pairs, and 26 mixed pairs. Each member of a pair was from the same population: 10 same-coil pairs and 4 mixed pairs from Morioahu; 24 same-coil and 22 mixed pairs from Uufau.

The mated snails were maintained as pairs for three months, during which all pairs were observed at intervals and their behaviour recorded. Courtship behaviour was classified as early or late, according to Lipton and Murray (1979). Copulations were recorded for all pairs, but full behavioural data were not recorded for 14 same-coil and 7 mixed pairs. This intermittent observation over a three-month period was adopted because attempts to increase the occurrence of courtship for intensive short-term observation resulted in hyperactivity of the snails. Since copulation in $P$. suturalis lasts for 5 to 65 minutes (Lipton and Murray, 1979), my observations included only a portion of all copulations occurring during the experiment. Since all pairs were observed during each 15 -minute period of observation, a relative measure of mating frequency was obtained.

The snails are ovoviviparous, generally giving birth to one young at a time. Some pairs had begun to produce young by the end of the three months, at which time all pairs were separated. The snails were then held individually in petri dishes, and their production of young was recorded for up to two years. Although $\boldsymbol{P}$. suturalis is a hermaphrodite, self-fertilization is rare (Murray and Clarke, 1976), so the recorded births indicate fertilities of the experimental matings. 


\section{(ii) Fertilities in natural populations}

To compare fertilities of rare and common morphs, adult $\boldsymbol{P}$. suturalis were collected in August 1979 from an area in western Haapiti Valley in which sinistrals make up less than ten per cent of the population. Control samples were collected from areas in adjacent Uufau Valley in which the frequencies of sinistral and dextral morphs were nearly equal. Each snail was isolated in the field and sent by air to the University of Western Australia. In the laboratory, the snails were kept isolated and their production of young recorded for 12 months.

Tests with rare morphs pose a statistical problem. In order to obtain sufficient numbers, it was necessary to collect snails over areas larger than the panmictic unit. Thus, if both morph frequency and fertility vary over space, a spurious correlation between the two could result, a problem which has not always been appreciated (see Clarke et al., 1978). To avoid this problem, I collected snails from $5 \times 5 \mathrm{~m}$ quadrats, and used only those samples which included both morphs. Samples from five quadrats with two to nine per cent sinistrals were combined for the low-sinistral area (sample sizes of 34 to 58). From each quadrat, all sinistrals and seven to ten randomly chosen dextrals per sinistral were included in the experiment. The statistical homogeneity of morph frequencies among these samples precludes spurious differences in fertilities between morphs. Similarly, the control snails were derived from three quadrats with 46 to 53 per cent sinistrals. The few snails that died during the 12 months of observation were excluded from the analysis of fertilities.

\section{Results}

Experimental matings from Morioahu and Uufau can be combined, as they showed the same trends and were not statistically different. Since the frequencies of copulations in dextral and sinistral pairs were not significantly different (table 1), they have been combined to allow simple comparisons between same-coil and mixed-coil matings. Copulations were observed in 15 of 34 pairs ( 44 per cent) of the same coil, but only 3 of 26 pairs (12 per cent) of opposite coil $\left(\chi_{1}^{2}=7.45, P<0.01\right)$. The average number of copulations for mixed pairs was only $\frac{1}{5}$ as great as for pairs with the same coil (table 1).

The rarity of copulations in mixed pairs was not due to infrequent courtship. Of the 19 mixed pairs for which full behavioural data were available, some courtship was observed in 17 , comparing well with 17 of 20 pairs of the same coil. For the pairs observed to court, no difference in total frequency of courtship (excluding copulation), was found for mixed

TABLE 1

Comparison of numbers of copulations observed for pairs of $\mathbf{P}$. suturalis with the same or different coil

\begin{tabular}{lrrrrrc} 
& \multicolumn{7}{c}{ Observed copulations } & U-Test \\
Mating Type & 0 & 1 & 2 & 3 & Mean & $P$ \\
D $\times$ D & 8 & 5 & 1 & 0 & 0.50 & $>0.50$ \\
S $\times$ S & 11 & 5 & 3 & 1 & 0.85 & \\
Same coil & 19 & 10 & 4 & 1 & 0.62 & $<0.025$ \\
Mixed coil & 23 & 3 & 0 & 0 & 0.12 &
\end{tabular}


TABLE 2

Average number ( \pm S.E.) of observations of courtship for courting pairs of $\mathrm{P}$. suturalis

\begin{tabular}{lcccc} 
Mating type & \multicolumn{3}{c}{$\begin{array}{c}\text { Courtship } \\
\text { Late }\end{array}$} & Total \\
Same coil & $n$ & Early & $2.28 \pm 0.38$ & $5.59 \pm 1.07$ \\
Mixed coil & 17 & $3.31 \pm 0.95$ & $2.89 \pm 0.84$ & $6.81 \pm 2.39$
\end{tabular}

and same-coil matings, although late courtship was actually more frequent in mixed pairs (table 2). The basis for the low frequency of copulation in mixed pairs is the orientation of the penis during probing. This orientation was towards the area of the genital pore in only three of 23 observations (13 per cent) for mixed pairs, compared with 18 of 20 observations $(90$ per cent) for pairs with the same coil.

Following separation of the mated snails, significant numbers of young were produced for more than a year. Throughout the period of productivity, mixed pairs tended to produce fewer young than did pairs of the same coil (fig. 1). Over a twenty-month period (including the mating period), this resulted in a decrease in fertility of about 28 per cent in mixed pairs compared with like pairs (fig. 1).

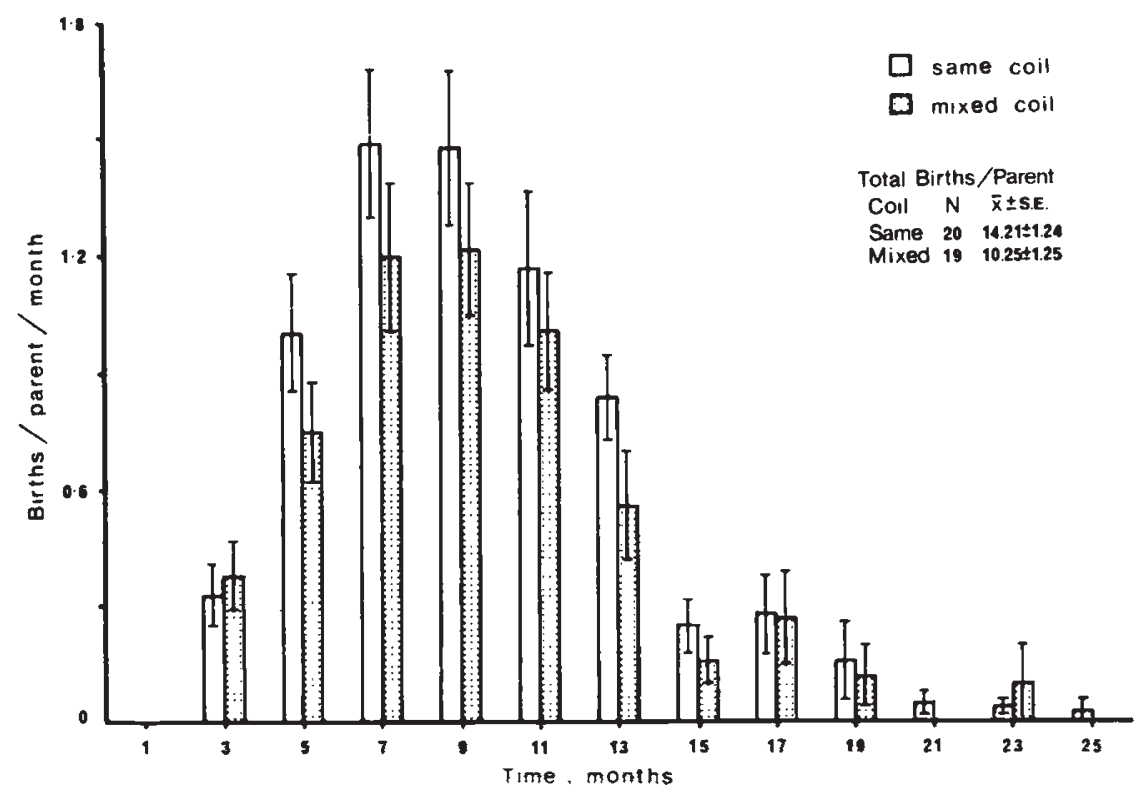

FIG. 1.-Birth rates for mixed-coil and same-coil pairs of $P$. suturalis. Values on the time axis are midpoints of two-monthly intervals since the pairs were placed together. Comparison of total births based on 20 months; $N$ is the number of pairs.

A similar result was obtained for fertilities of wild-caught adults (table 3). Sinistral snails from the area in which sinistrals occurred at low frequency produced an average of 41 per cent fewer young than their high-frequency dextral counterparts. This was not due to inherently low fertility of sinistrals, as sinistral and dextral snails produced similar numbers of young when the two morphs occurred in similar frequencies (table 3 ). 
TABLE 3

Average number of young produced in one year by sinistral $(S)$ and dextral $(D)$ P. suturalis from populations with different frequencies of $S$

\begin{tabular}{crcccc} 
& S & \multicolumn{1}{c}{ D } & \\
& $\bar{x} \pm$ S.E. & $n$ & $\bar{x} \pm$ S.E. & $n$ & $t$ \\
$\mathrm{~S}<10 \%$ & $7 \cdot 00 \pm 1 \cdot 89$ & 10 & $11 \cdot 90 \pm 0 \cdot 51$ & 79 & $2 \cdot 59^{* *}$ \\
$45 \%<\mathrm{S}<55 \%$ & $11 \cdot 91 \pm 1 \cdot 13$ & 24 & $12 \cdot 24 \pm 1 \cdot 05$ & 21 & $0 \cdot 21$ \\
${ }^{* *} p<0.01,1$ - tailed. & & & & &
\end{tabular}

\section{Discussion}

Lipton and Murray (1979) showed that pairs of $P$. suturalis with opposite coils attempt intromission in the wrong place. They also observed no copulations in mixed pairs, although small sample sizes rendered this absence non-significant when compared with the frequency of copulations in pairs with the same coil. The present results complement and extend those of Lipton and Murray, confirming substantial reproductive isolation due to chirality. Clarke and Murray (unpublished) have data indicating assortative mating within polymorphic populations of $P$. suturalis, confirming partial reproductive isolation in the field.

Clarke and Murray (1969) proposed that the populations of dextral $P$. suturalis resulted from reproductive character displacement in the presence of the sinistral species $\boldsymbol{P}$. mooreana. Hybrids between these species have abnormal genitalia, implying postmating isolation (Murray and Clarke, 1980). Selection against hybrids, combined with the isolating effect of shell coil, provides the necessary mechanism for character displacement as the cause of the area effect for dextral $P$. suturalis.

The geographic distribution of hybridisation within the $P$. suturalis species complex provides further evidence for an isolating effect of chirality (Murray and Clarke, 1980). Monomorphic dextral populations of $P$. suturalis coexist with the sinistral species $P$. mooreana, $P$. tohiveana and $P$. olympia apparently without hybridisation. Likewise, monomorphic sinistral populations of $P$. suturalis coexist with the dextral species $P$. aurantia without hybridisation. $P$. aurantia and $P$. olympia have non-overlapping distributions, and the area in which they approach each other corresponds with a transition from sinistral to dextral $P$. suturalis. It is in this transition zone that $P$. suturalis hybridises with both $P$. aurantia and $P$. olympia (Murray and Clarke, 1968, 1980). Thus, all of the evidence from the field and laboratory is consistent with an effect of chirality on reproductive isolation, and with the interpretation that the dextral populations of $P$. suturalis are the result of character displacement.

A difficulty, however, is that such character displacement opposes stabilizing selection within $P$. suturalis. The reduced fertility observed for mixed-coil mating implies that the frequency of copulation affects fitness. Thus, although sinistral and dextral individuals may be physiologically equivalent, selection in polymorphic populations will be against the less common morph, because the less common morph is less likely to mate. The reduced fertility of low-frequency sinistral $P$. suturalis from Haapiti confirms the occurrence of selection against the rare morph. Such positive frequency dependent selection resulting from assortative mating promotes 
monomorphism (Moore, 1979), and reduces the likelihood of change from one coil type to the other.

In order for populations of dextral $P$. suturalis to have evolved from sinistral ancestors as a result of character displacement (Clarke and Murray, 1969; Murray and Clarke, 1980), selection against hybridisation must have overcome the stabilizing effect of selection against the initially rare dextral morph. This is possible if $P$. suturalis was less common than $P$. mooreana during the change from sinistrality to dextrality. In that case, and in the absence of other behavioural isolating mechanisms, sinistral $P$. suturalis would have been more likely to mate with $P$. mooreana than with conspecifics, with a consequent large reduction in fertility. This reduction would result in an advantage to the dextral morph, overcoming its disadvantage associated with rarity. Once the dextral morph reached a frequency greater than 50 per cent, both positive frequency dependent selection and selection against hybridisation would ensure the rapid fixation of dextrality. The feasibility of such selection has been confirmed by models of selection of assortative mating genes with pleiotropic effects along an environmental gradient (Moore, 1981).

Although the area effect in $P$. suturalis can be explained entirely in terms of the shell coil polymorphism, it is conceivable that the reduced fertility of mixed pairs in the laboratory and of low-frequency sinistrals in the wild is due to other genetic differences. In other words, it is possible that the clines between monomorphic populations of sinistral and dextral $P$. suturalis are really hybrid zones. Evidence for assortative mating within the mixed populations implies an opportunity for genetic divergence between sinistral and dextral subpopulations. Substantial genetic divergence associated with area effects for shell morphs has been found in Partula taeniata (Clarke, 1968) and Cepaea nemoralis (Johnson, 1976; for a counter example, see Jones et al., 1980). Thus, although the evidence for selection against the rare coil type in $P$. suturalis is conclusive, the mechanism may involve more than the effects of coil alone.

Regardless of the exact mechanism, however, positive frequency dependent selection will ensure the stability of the area effect, since infiltration by either morph into the area of high frequency of the alternative morph will be prevented. Interestingly, this stability is independent of the mechanism of origin of the area effect, as it does not require inherently higher fitness of either morph in its region of high frequency.

This stabilizing effect of positive frequency dependent selection may be important in other narrow transition zones. For example, post-mating isolation in the absence of premating isolation will result in selection against the rarer species. A more specialized example is in Heliconius butterflies, in which positive frequency dependent selection due to Müllerian mimicry maintains narrow hybrid zones between geographic races (Turner, 1971; Brown et al., 1974). Conceivable situations involving premating isolation may be found in frogs and crickets, for example, in which a rare-type male in a mating chorus might have difficulty in attracting conspecific females. Narrow and apparently stable hybrid zones have been explained in terms of migration and selection with respect to the local environment (Moore, 1977). The area effect for direction of coiling in $P$. suturalis indicates that another potential explanation is positive frequency dependent selection. 
Acknowledgements.-I am grateful to Profs. B. C. Clarke and J. J. Murray and to Dr J. D. Roberts for comments. The snails were carefully and laboriously tended by $\mathrm{L}$. Collins, J. Dolva, L. Forrest and P. M. Middleton. Funds were provided by the Australian Research Grants Committee.

\section{REFERENCES}

BROWN, K. S., SHEPPARD, P. M. AND TURNER, J. R. G. 1974. Quaternary refugia in tropical America: evidence from race formation in Heliconius butterflies. Proc. $R$. Soc. Lond. B., 187, 369-378.

CLARKE, B. 1968. Balanced polymorphism and regional differentiation in land snails. In Drake, E. T. (ed.) Evolution and Environment, Yale University Press, New Haven, pp. 351-368.

CLARKE, B., AND MURRAY, J. 1969. Ecological genetics and speciation in land snails of the genus Partula. Biol. J. Linn. Soc., London, 1, 31-42.

CLARKE, B., ARTHUR, W. HORSLEY, D. T., AND PARKIN, D. T. 1978. Genetic variation and natural selection in pulmonate molluscs. In Fretter, V., and Peake, J. (eds.) Pulmonates, Vol. 2A, Academic Press, New York, pp. 219-270.

CRAMPTON, H. E. 1916. Studies on the variation, distribution, and evolution of the genus Partula. The species inhabiting Tahiti. Carnegie Inst. Washington Publ., 228, 1-311.

CRAMPTON, H. E. 1932. Studies on the variation, distribution, and evolution of the genus Partula. The species inhabiting Moorea. Carnegie Inst. Washington Publ., 410, 1-335.

JOHNSON, M. S. 1976. Allozymes and area effects in Cepaea nemoralis on the western Berkshire Downs. Heredity, 36, 105-121.

JONES, J. S., SELANDER, R. K., AND SCHNELL, G. D. 1980. Patterns of morphological and molecular polymorphism in the land snail Cepaea nemoralis. Biol. J. Linn. Soc., London, 14, 359-387.

LIPTON, C. S., AND MURRAY J. 1979. Courtship of land snails of the genus Partula. Malacologia, 19, 129-146.

MOORE, W. S. 1977. An evaluation of narrow hybrid zones in vertebrates. Quart. Rev. Biol., $52,263-277$.

MOORE, W. S. 1979. A single locus mass-action model of assortative mating, with comments on the process of speciation. Heredity, 42, 173-186.

MOORE, w. S. 1981. Assortative mating genes selected along a gradient. Heredity, 46, 191-195.

MURRAY, J., AND CLARKE, B. 1966. The inheritance of polymorphic shell characters in Partula (Gastropoda). Genetics, 54, 1261-1277.

MURRAY, J., AND CLARKE. B. 1968. Partial reproductive isolation in the genus Partula (Gastropoda) on Moorea. Evolution, 22, 684-698.

MURRAY, J., AND CLARKE, B. 1976. Supergenes in polymorphic land snails. II. Partula suturalis. Heredity, 37, 271-282.

MURRAY, J., AND CLARKE, B. 1980. The genus Partula on Moorea: speciation in progress. Proc. R. Soc. Lond. B, 211, 83-117.

TURNER, J. R. G. 1971. Two thousand generations of hybridisation in a Heliconius butterfly. Evolution, 25, 471-482. 